\title{
Truce and a German director for CERN
}

PROFFSSOR Herwig Schopper, presently director of the Deutsche Elektronen Synchrotron Laboratory (DESY) near Hamburg, has been designated directorgeneral of the European sub-nuclear physics laboratory, CERN, Geneva. He will succeed the present joint directorsgeneral, Leon Van Hove and John Adams, on 1 January 1981.

The appointment has not been without its drama. The Italian delegation, one of the 12 national representations on CERN's governing Council, had been refusing to acceed to Schopper's appointment until possible conflict between future CERN and DESY programmes is resolved. But after an extraordinary statement from CERN and another from the Italian Ministry of Science, the air was cleared last week.

The CERN statement describes the meeting of the Committee of Council on 29 February. The programme for the construction of LEP, the large electronpositron collider which is CERN's next major project, was raised.

The statement said:

"The delegates at the Committee of Council agreed with the Italian delegation that LEP must have the top priority among the European accelerator projects in elementary particle physics, and that it should be built as soon as possible. The delegates also agreed, following an Italian proposal, that a study group be formed to discuss certain legal and budgetary problems and the relation of LEP to national programmes . .

"The Committee of Council entrusted Professor Schopper with the mandate to present Council, at its session in June 1980, with his proposals concerning the top management structure and the directing staff of CERN ...."

The 'legal and budgetary problems' refer to the question of whether LEP could be built within CERN's present budget, without declaring LEP as a project requiring special funding. The 'national programmes' referred to mean largely HERA, a proposal at DESY to build an electron-proton collider; its inclusion in the CERN text is something of a coup for Italy, which has been worried that HERA would compete with LEP.

In fact on many issues Germany and Italy have come extremely close, both wanting to push LEP along as fast as possible, at the lowest practical budget.

"I believe we can build the first version of LEP to give beam at the end of 1986", Schopper said on Monday. He will now participate actively in constructing the final proposal for LEP, which will be made to Council in June.

Whether LEP will be a CERN supplementary programme, in which the participation of individual countries is optional, or part of the basic programme, in which it is not, is a crucial question, Schopper believes. "We must try to activate all scources inside CERN", he said, "and that requires flexibility to transfer people from one project to another'. But if LEP is merely a supplementary programme, flexibility will be difficult to achieve.

Schopper thinks that LEP can be built "within a few per cent" of the current CERN budget of SF 590 million a year.

Italy reacted to CERN's announcement with its own statement. The Science Minister, Vito Scalia, said last week:

"... we are finally approaching the solution to defining the programmes of CERN. This has been the aim of the Italian government since November. . .

"For the first time in 25 years, CERN had found itself in difficulties in defining its programme against serious competition from other national laboratories. By the end of last year, the pressures we had been applying to reach a rapid clarification of these problems had had no appreciable result. Council opposed our proposal to discuss the future of CERN, and the Italian delegation decided to underline its dissent. [The delegation walked out of the December Council meeting, an event unprecedented in CERN history. The meeting was to have appointed Schopper.]

"But last week the Committee of Council demonstrated unequivocally that our action, which was intended to give priority to the discussion of CERN programmes over and above the appointment of a new director-general, was fully justified . . .

"All delegates at the meeting of 29 February have given LEP an absolute priority so the new accelerator will probably be built in five years. This decision allows the laboratory to keep its position of pre-eminence and confirms the validity of the "active Europeanism" that the Italian government has done its best to promote in international research.

"In view of this development it is clear that the recent solution of the CERN case represents a success for my country . . . It clarifies also why the Italian delegation is now disposed to vote for Professor Schopper ...." Robert Walgate

\section{Interferon}

\section{US company increases production ten-fold}

THE US drug company G D Searle \& Co announced last week that it plans to increase its fibroblast interferon production "six to tenfold" by the middle of 1981. Facilities are also being set aside for conjectured production by genetically engineered Escherichia coli. A new plant will be built at Searle's High Wycombe, UK, factory.

"But this project is purely for research and development", says Searle's director of research and biological development at High Wycombe, Dr Brian Richards. "It will cost us $£ 6.75$ million, and we don't intend to make a profit out of it".

Searle's increased fibroblast interferon production will be supplied to the Anderson Hospital of the University of Texas for clinical tests of the drug in cancer control. The trial has been designed to match an earlier one with leukocyte interferon; it is the first on cancer patients with interferon from fibroblasts, although there has been a successful trial on patients suffering from herpes keratitis of the eye (where the application was external). The difference between fibroblast and leukocyte interferon is not just that they come from different kinds of cells. By several laboratory criteria they also differ in structure. What is not yet clear is whether this will affect their therapeutic value.

Two-thirds of the space in the new plant will be set aside on a conjecture: that within 18 months strains of genetically engineered Escherichia coli will exist which can compete with fibroblasts in interferon production.

"Charles Weissmann in Zurich has produced $E$. coli which manufacture one or two molecules of interferon per cell," says Dr Richards. "I'm quite satisfied he has the right gene product, but the problems are going to come in trying to improve the efficiency."

Searle has in fact constructed bacteria carrying other genes that are expressed with high efficiency - "we have cells producing haemagglutinin at $1 \%$ of total protein of the cell" says Richards. Enough is not yet known about expression efficiency to predict whether such bacteria containing the interferon gene in place of the haemagglutinin gene, would be equally efficient, but apparently it gives "cause for hope".

Searle's current interferon production is roughly one quarter of world production, including leukocyte interferon, he estimates. So with the increased fibroblast production alone, world interferon production will increase two or three-fold. "Ultimately costs might fall by a factor of 100 to 1000", Richards estimates. Interferon costs would then be on a par with those of antibiotics. 